\title{
The Diverse Housing Needs of Rural to Urban Migrants and Policy Responses in China: Insights from a Survey in Fuzhou
}

\author{
Liyue Lin and Yu Zhu
}

\begin{abstract}
Based on a survey of rural-urban migrants and subsequent in-depth interviews in Fuzhou, the capital city of Fujian Province in China, this article first provides a brief review of migrants' housing conditions, and assesses the current approaches in meeting their housing needs and security. We then examine migrants' housing needs in the context of their mobility and their diversified migration flows, demonstrating that migrants have different housing needs from local urban residents, and among themselves. The article also explores the policy implications of this analysis, and makes policy recommendations, focusing mainly on redefining the roles of the state and the necessity of making policies to meet the diversified needs of rural-urban migrants in the provision of housing and housing security.
\end{abstract}

\begin{abstract}
1 Introduction
The social protection needs of rural-urban migrants (henceforth migrants) have been increasingly recognised by China since the beginning of the new century. Various efforts have been made to protect migrants' rights in terms of employment and pay, to get them covered by various social insurance programmes, and to provide more equal educational opportunities to their children. While progress has been made in the above areas to different degrees, providing housing security to migrants is still a relatively neglected issue. Currently, the main responsibility for such provision rests upon the shoulders of migrants themselves and on their employers. Furthermore, the limited roles of the state in such provision have been in extending the urban housing benefits and security to migrants, assuming that rural-urban migration is a one-way process, and that migrants all desire to settle down in destination cities.
\end{abstract}

As we will see in more detail below, such an approach is not adequate in meeting migrants' needs for housing provision and security, especially in the context of their diversified migration flows. New approaches, which are able to meet migrants' diversified housing needs and enable the state to take more responsibility in meeting such needs, are urgently required.

Based on a survey of migrants and subsequent indepth interviews with them, their employers, and officials of relevant government departments, undertaken in early 2009 in Fuzhou, this article contributes to tackling the above issues. The survey covered 600 migrants, half of whom worked in industrial, trade and service enterprises; more than 100 of them employees in Fuzhou's major industrial zones and commercial areas, and 300 engaged in informal employment as street vendors, motor-bike-taxi drivers, porters, day labourers, and informal small enterprises. The quota sampling method was used to select the respondents in both formal and informal employment, and a sampling framework with stratification across migrants' major occupational categories was developed to guide the sampling process. The in-depth interviews were with a government official in a relevant government department, three migrant employers and 18 migrants in both formal and

IDS Bulletin Volume 41 Number 4 July 2010 @ 2010 The Authors. Journal compilation (c) Institute of Development Studies Published by Blackwell Publishing Ltd, 9600 Garsington Road, Oxford OX4 2DQ, UK and 350 Main Street, Malden, MA 02148, USA 

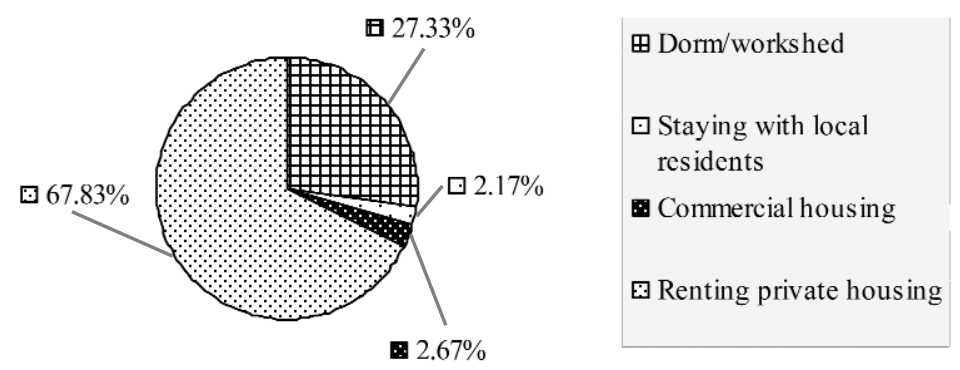

informal employment. This article will first provide a brief description of migrants' housing conditions and the current approaches to their housing security. We will then examine migrants' needs for housing provision and security in the context of their mobile nature and their diversified migration flows. Finally, we will explore the policy implications of the above analysis, and make policy recommendations, focusing mainly on redefining the roles of the state and the necessity of making policies to meet the diversified needs of rural-urban migrants in the provision of housing and housing security.

\section{Current conditions and approaches in migrants' housing 2.1 Migrants' housing conditions}

Housing is an important aspect of the basic needs for migrants in the cities. However, most migrants in China are disadvantaged in this respect, especially compared with local urban residents. This is first reflected in the fact that they are excluded from almost all sources of government-subsidised housing provision, and have very few choices in terms of housing in the destination cities. As Wu (2002) notes, urban residents are able to obtain accommodation through one of three methods: buying the property right, or paying higher rent, for their publicly assigned apartments; acquiring commercial housing through the market; and participating in affordable housing projects. A limited number of low-income urban families have the further option of obtaining subsidised low-rent housing. Apart from commercial housing purchased through the market, all the other forms of housing provision are subsidised by the government. These subsidies are based on local hukou (household registration) status, and therefore exclude most migrants, who do not have urban hukou status (Wu 2002). Given the very high price of commercial housing and the limited financial capacity of migrants, buying commercial housing through the market is usually not a realistic option.

Thus, many studies reveal that the most common form of accommodation for migrants is rental housing, followed by dormitories provided by their employers (e.g. Wu 2002; Lin and Zhu 2008). This situation is confirmed by our survey in Fuzhou. As can be seen from Figure 1, most of the respondents in the Fuzhou survey obtained their accommodation in these two ways, with only 2.67 per cent of them living in owneroccupied housing. This is in strong contrast to the local urban residents. A survey in Fujian Province shows that 64 per cent of local urban residents had owner-occupied housing (Lin and Zhu 2008). Furthermore, 91.33 per cent of our respondents had no access to any component of the housing security system in Fuzhou. All this suggests that the current system of urban housing provision and security in China takes little consideration of migrants' housing needs, and that migrants have to rely on themselves and their employers instead.

Migrants' disadvantaged housing situation is also reflected in the size and quality of their dwellings. In our survey in Fuzhou, the per capita usable area of respondents' housing was 11.97 square metres, only one-third of the per capita usable area of Fuzhou local residents' housing (Lin and Zhu 2008). Although most of the respondents had access to tap water and used gas 
and electricity for cooking, the proportion of them having a kitchen (especially a private one) was low, at only 44.17 per cent. Furthermore, nearly one-third of the respondents did not have a private lavatory, and more than two-thirds had to share bathrooms, or even had no bathroom at all. The housing facility index, ${ }^{1}$ which measures housing quality, is 0.6756 for our respondents. This is significantly lower than that for Fuzhou's local residents (0.85) (Lin and Zhu 2008); and furthermore, the indices for 35 per cent of our respondents were below 0.5 . Clearly, migrants' housing conditions are poor, and much needs to be done to meet their basic housing needs.

\subsection{Current policy approaches}

In the last few years, migrant housing has started to attract attention in government policymaking. In 2005, migrant housing was listed as a key priority for the Ministry of Construction. This was the first time that the issue had become part of the agenda of the Ministry (Liang 2005). In 'Opinions of the State Council about solving the problems of rural-urban migrant workers', released in 2006, the State Council gave the further instruction 'to improve housing conditions of the floating population' (The State Council 2006). At the end of 2007, the Ministry of Construction and four other ministries jointly issued a document entitled 'Guiding opinions on improving migrant workers' housing conditions', in which, for the first time, it is stipulated that governments at various levels should incorporate the housing issues of migrant workers who live and work in cities on a long-term basis into urban housing planning (Ministry of Construction, National Development and Reform Commission, Ministry of Finance, Ministry of Labour and Social Security and Ministry of Land and Resources 2007). In the meantime, in a document issued by the Ministry of Construction, Ministry of Finance and People's Bank of China, it was stipulated that rural-urban migrant workers may join the public reserve fund for housing, if certain conditions are met (Ministry of Construction, Ministry of Finance and People's Bank of China 2005).

Based on the above principles, government at different levels has taken various measures to meet migrants' housing needs. These measures can be divided into the following three approaches: the inclusive, the independent and the hybrid. In the case of the inclusive approach, attempts have been made to include a small proportion of migrants, who meet certain conditions, such as having permanent jobs and being regarded as 'excellent rural-urban migrant workers', into the existing urban housing security system (Ministry of Construction, Ministry of Finance and People's Bank of China 2005; Jiang, Luo and Wang 2008). The independent approach requires developing specific housing policies for migrants. The main effort is for migrants' employers, with the cooperation of local authorities, to develop lowrent or free housing compounds for provision only to migrants and their families, to set up and implement building, sanitation and environmental standards for migrant housing, and to enact regulations to enhance the management and services of rental housing for migrants (Zhu and Zhu 2007). In the case of the hybrid approach, the practice has been for local authorities to develop low-rent or free housing in the industrial parks for migrants, working in cooperation with migrant employers and using funds from the governments allocated for such housing projects (Du 2008).

The above efforts certainly represent a step forward in meeting migrants' housing needs; however, their limitations are evident. First, as mentioned earlier, the main responsibility for housing provision still rests with migrants themselves and their employers. In fact, in the document issued jointly by the Ministry of Construction and four other ministries at the end of 2007 and cited above, it is stipulated that work units or enterprises are the main institutions responsible for improving the housing conditions of rural-urban migrant workers, and indeed this is the case in both the independent and hybrid approaches just mentioned. Thus, local governments of migrant destination cities have been increasingly involved in such efforts. However, their role in such provision is often seen as something 'additional' to their usual housing provision to local urban residents, and the results have had limited effects on improving conditions. In fact, both the independent and hybrid approaches suffer from this limitation, with the former representing only some improvement over the accommodation provided by migrants' employers, and the latter only benefiting a limited group of migrants in a specific type of location, i.e. the industrial parks. In our interviews with an official from the relevant government department in Fuzhou, we 
were told that providing housing security to rural-urban migrants is not their duty. It is done on an optional rather than compulsory basis, and is heavily dependent on the will and financial capacity of the relevant local governments (indepth interview, record of the authors No. 10, July 2009). This confirms the limited and ad hoc role of the state in providing housing security to rural-urban migrants.

The inclusive approach, in which the state plays a more significant role, is urban-hukou and residence-based, and involves extending urban housing benefits and security to rural-urban migrants. Such an approach can only benefit a small group of migrants who meet certain conditions, and therefore its effects on the majority of rural-urban migrants are limited. More importantly, as mentioned earlier, such an approach is based on the simplistic assumption that migrants will eventually settle in the destination cities and have the same needs as those of local urban residents. Such an assumption neglects the fact that migrants have distinctive housing issues, which arise from their mobile nature and their socioeconomic characteristics, including instability of employment and low income. Furthermore, both their migration flows and their housing needs vary, due to the availability of different choices of final migration destinations. All this poses challenges to China's current policies and practices, and calls for new approaches beyond the simple extension of urban housing benefits and security to migrants. In fact, migrants' distinctive and varying housing needs also require more state involvement in providing housing security to them, as we will see in more detail later. Therefore, a better understanding of mobility patterns is crucial for the exploration of new approaches. In the following section, we will first examine the various migration flows, and then explore their implications for migrants' housing security.

\section{Migration flows and their implications for housing security policies 3.1 Migrants' diversified migration flows}

Conventionally, rural-urban migration has often been conceptualised as a rural-urban one-way process (Zhu and Chen 2010). In the case of China, although there has long been a recognition of migrants' mobile and unsettled nature, this is often attributed to the barriers caused by China's hukou system (e.g. Chan and Zhang 1999; Solinger 1999; Liang 2001). The assumption underlying this is that without the hurdles caused by the hukou system, most migrants would settle down in the cities, and their integration there would answer their needs for housing security.

However, migration is not always a one-way rural-urban process. Our recent surveys in migrant destination cities in Fujian suggest that a substantial proportion of migrants chose to return to their hometowns or to remain mobile in the foreseeable future, while only a small proportion of them want to settle down in the cities where they were living and working (Zhu 2003; 2007; Zhu and Chen 2010). Furthermore, their settlement intentions were determined not only by their hukou status, but also by other factors at both the demand (employer) and supply (migrant) sides of the labour market, including migrants' demographic characteristics, employment conditions, household income, and the conditions of their places of origin and destination (Zhu 2007, Zhu and Chen 2010). Our 2009 Fuzhou survey provides further evidence confirming the diversified mobility patterns of rural-urban migrants.

When answering the question 'if you had a free choice, what would be your long-term plan?', 42.17 per cent of the respondents said they would choose to continue to work in their current destination cities for a while and then return to their hometowns; 7.83 per cent would choose to continue to circulate between their places of origin and destination; 8.83 per cent would choose to continue to work in their current destination cities for a while and then move to other cities and only 19.17 per cent would choose to settle in their current destination cities; 22 per cent felt it was difficult to make a decision.

It is also important to note that the above low settlement intention of the respondents in their current or future destination cities is not only caused by the barriers of the hukou system and other related institutional constraints. In fact, when answering the question in the same survey 'if you were qualified (allowed) to transfer the hukou of your family to the destination, what would be your choice?', the majority of the respondents said they would choose to keep their hukou in their hometowns, and those who would 


\begin{tabular}{lllll}
\hline Table 1 Housing needs of respondents in destination cities by their settlement intentions $(\mathbf{\%})$ \\
\hline Housing needs & $\begin{array}{l}\text { Settling down } \\
\text { in the cities } \\
(\boldsymbol{n}=\mathbf{1 6 8})\end{array}$ & $\begin{array}{l}\text { Circulating } \\
(\boldsymbol{n}=\mathbf{1 7 9})\end{array}$ & $\begin{array}{l}\text { Returning to } \\
\text { hometowns } \\
(\boldsymbol{n}=\mathbf{2 5 3})\end{array}$ & Total $(\boldsymbol{n}=\mathbf{6 0 0})$ \\
\hline Commercial housing & 19.05 & 6.70 & 3.56 & 8.83 \\
'Affordable housing' & 25.60 & 22.91 & 9.49 & 18.00 \\
Low-rent housing & 25.60 & 29.61 & 43.48 & 34.33 \\
Free accommodation provided by employers & 23.21 & 32.40 & 31.23 & 29.33 \\
Housing for migrant couples provided by & 2.98 & 5.03 & 8.30 & 5.83 \\
employers & 0.60 & 1.12 & 1.19 & 1.00 \\
No specific need & 2.98 & 2.23 & 2.77 & 2.67 \\
No idea & 100 & 100 & 100 & 100 \\
Total & & &
\end{tabular}

Note: $X^{2}=66.562, p<0.001$.

Source The 2009 Fuzhou survey of the authors.

choose to transfer the hukou of the whole family to the destination or to transfer only their own hukou to the destination accounted for only 24.03 per cent and 7.83 per cent of the respondents, respectively. This result is consistent with the settlement intentions of our respondents as previously noted. Such an understanding of rural-urban migration is new and has important implications for migrants' housing provision, as we will see below.

\subsection{Migrants' varying housing needs}

Such implications are first reflected in the fact that migrants' mobile nature and the diversification in their migration flows affect their demands for housing provision. As Table 1 shows, two characteristics feature strongly in migrants' housing demands, according to the results of our Fuzhou survey. The first is the low standards of housing that migrants seek. The two most common types of housing needs expressed were for low-rent housing and free accommodation provided by employers. In contrast to local urban residents, owner-occupied housing, including both the governmentsubsidised 'affordable housing' and commercial housing, were not migrants' priority choices. This is obviously due to their high level of mobility, the instability of their employment, and their low income level, whose combined effects not only constrain their ability to settle down, but make owner-occupied and relatively high-standard housing not a cost-effective choice for them.

In Table 1 the category of 'settling down in the cities' refers to those who chose to settle down in the current destination city and those who chose to work in the current destination city for a while and then move to another city. The category of 'circulating' refers to those who chose to continue to circulate between places of origin and destination and those who felt it was difficult to make a decision. The category of 'returning to the hometowns' refers to those who chose to continue to work in the current destination city for a while and then return to their hometowns.

The second characteristic of migrants' housing demands is its diversified nature. While cheap and low-standard housing dominated the responses, it is noticeable that 'affordable housing' and commercial housing together constituted 26.83 per cent of housing choices, in contrast to the actual availability of housing for migrants, as shown in Figure 1. These differing needs are closely related to migrants' range of settlement intentions in their future migration. As we can see from Table 1, for those who intended to settle down in the cities, 'affordable housing' ranked first in terms of demand, together with low-rent housing, and 'affordable housing' and commercial housing together constituted 44.65 per cent demand. This is in strong contrast to those who intended to return 


\begin{tabular}{|c|c|c|c|c|}
\hline $\begin{array}{l}\text { Policies for providing housing security to } \\
\text { rural-urban migrants }\end{array}$ & $\begin{array}{l}\text { Settling in } \\
\text { destination city } \\
(n=168)\end{array}$ & $\begin{array}{l}\text { Circulating } \\
(n=179)\end{array}$ & $\begin{array}{l}\text { Returning to } \\
\text { hometown } \\
(n=253)\end{array}$ & $\begin{array}{l}\text { All migrants } \\
(n=600)\end{array}$ \\
\hline Free employer-provided accommodation & 11.18 & 15.00 & 15.53 & 14.33 \\
\hline $\begin{array}{l}\text { Employer-provided housing for migrant } \\
\text { couples }\end{array}$ & 4.12 & 4.17 & 8.41 & 5.92 \\
\hline Low-rent housing & 14.15 & 15.76 & 19.66 & 16.89 \\
\hline Rental subsidy & 28.74 & 27.77 & 29.91 & 28.87 \\
\hline Entitlement to 'affordable housing' & 12.34 & 11.73 & 5.40 & 9.14 \\
\hline $\begin{array}{l}\text { Entitlement to the public reserve fund for } \\
\text { housing }\end{array}$ & 11.65 & 7.39 & 6.67 & 8.18 \\
\hline Loans and preferential treatment in taxation & 15.66 & 11.03 & 4.71 & 9.88 \\
\hline Housing standards for migrant dormitories & 2.16 & 7.16 & 9.70 & 6.78 \\
\hline Total & 100 & 100 & 100 & 100 \\
\hline
\end{tabular}

*Each respondent could choose three answers and rank them first, second and third. Each figure in the table is the weighted average of these responses, with weights of $0.5,0.3$ and 0.2 , respectively.

Source 2009 Fuzhou survey by the authors.

to their hometowns. Their demand was highly concentrated within the two typical housing types for rural-urban migrants, i.e. low-rent housing and free accommodation provided by employers. Understandably, the housing needs stated by those who expected to keep circulating was something between the above two types. Thus there are clear internal differences in housing needs among migrants, corresponding to the three-way split in their settlement intentions.

\subsection{Distinctive and diverse demands for housing security policies}

Diverse migration patterns are also reflected in migrants' differentiated needs for housing security policies. As can be seen from Table 2, providing a rental subsidy was ranked first as a policy need not only by the respondents as a whole, but also for all three groups according to settlement intentions. Low-rent housing and the provision of free accommodation by employers ranked second and the third for the respondents as a whole, however not as consistently as the first need, since those intending to settle in the cities had different second and third-ranked policy priorities. In general, policies facilitating low cost, shorter-term housing feature strongly in migrants' needs, while housing security policies for local urban residents, including 'affordable housing' and the public reserve fund, were not regarded as important by most respondents. Again, this is consistent with the mobile nature of most migrants and their unstable employment and low income level, further underlining that migrants have different needs from local urban residents.

Further analysis of Table 2 reveals the internal differences in migrants' needs for housing security policies. Such differences can be examined on four different levels, as demonstrated in Figure 2. At the level of first priority, the needs of all three groups are highly consistent. They all chose 'providing rental subsidy' as the most important housing security policy. However, respondents' choices start to vary with their second priority. Although 'providing low rent housing' was the choice of all three groups, some wanted to settle down in the destination city, while others wanted to keep circulating or return to their hometown. For the former group, their settlement intention implies that they would need to purchase owneroccupied housing sooner or later, and therefore they were in more need of the policy of 'providing loans and preferential treatment in 


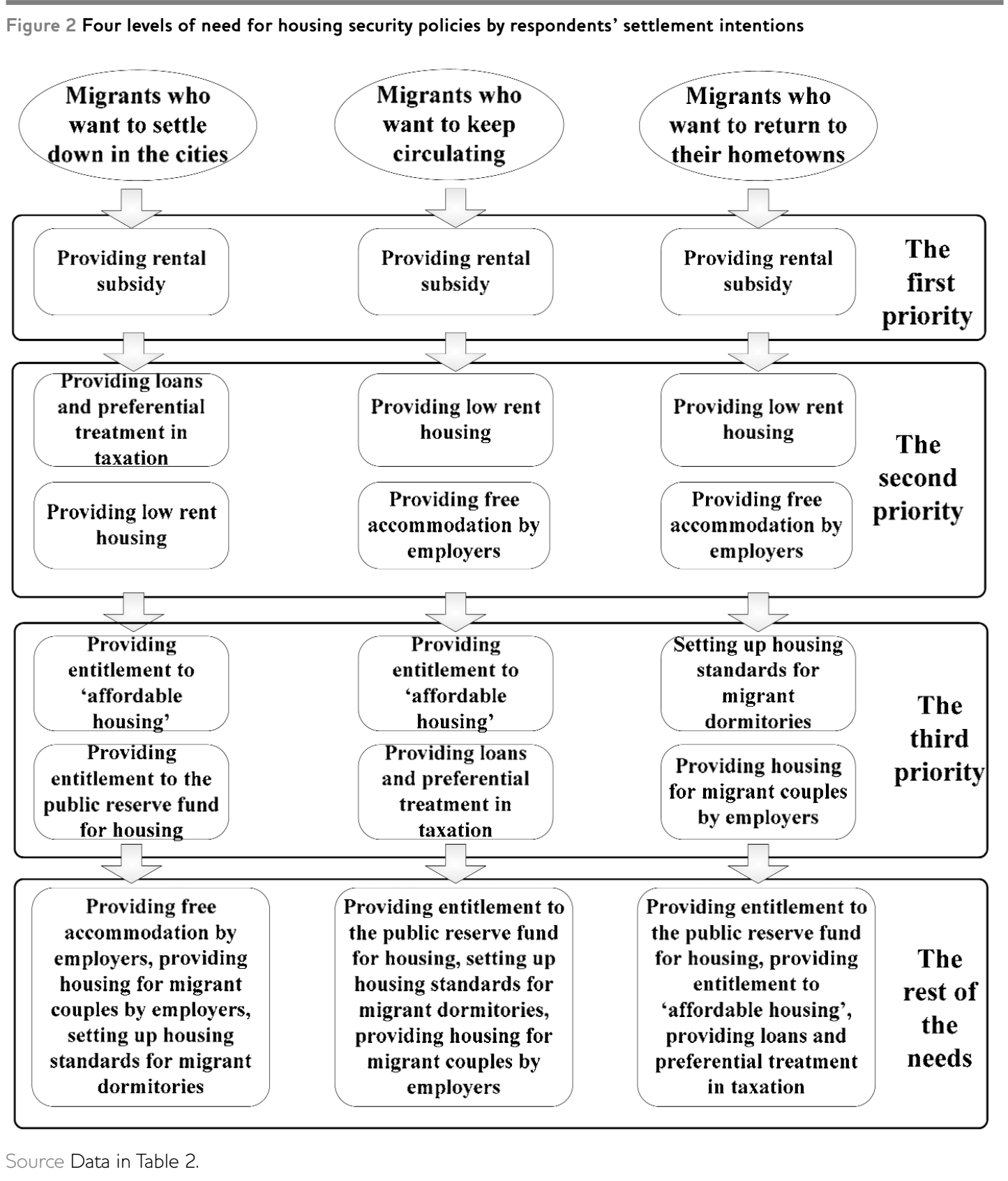

taxation'. For the latter groups, 'provision of free accommodation by employers' could reduce their expenses at destination, and was more suitable for their temporary stay. At the third priority level, the need for policies ensuring stable owneroccupied housing is even more evident for those who wanted to settle, since they chose 'providing entitlement to "affordable housing"" and 'providing entitlement to the public reserve fund for housing'. However, those who wanted to return to their hometowns still chose the policies that would improve housing during their temporary stay and lower their housing costs at destination, i.e. 'setting up housing standards for migrant dormitories' and 'provision of housing for migrant couples by employers'. Interestingly, the needs of those who wanted to keep circulating started to converge with those of migrants who wanted to settle down at destination. Only at the fourth and lowest level of priority did policies facilitating low-cost and temporary housing start to attract the attention 
of those who wanted to settle down at destination again; while those who wanted to return to their hometowns started to demonstrate some interest in policies facilitating more stable and owner-occupied housing. Understandably, those who wanted to keep circulating expressed needs between those of the above two groups.

The above analysis provides important guidance for the development of housing security policies for migrants. Overall, migrants' needs for housing provision and security are significantly different from those of local urban residents. Their housing needs are concentrated around the low-cost and rental accommodation, and therefore commercial housing and government subsidised 'affordable housing' are not suitable for most of them. Policies responding to their low-cost housing needs, such as 'providing rental subsidy' and 'proving low-rent housing', are what they most need, and they may not necessarily benefit from the simple extension of housing security policies targeting local urban residents. At the same time, it is important to note that migrants are not a homogeneous group, and their needs for housing security are closely related to their future settlement intentions. While the needs of those who want to settle in their destination city can be met by policies similar to those targeting local urban residents, policies should be created to facilitate the lowcost and temporary housing needs of those who want to return to their hometowns. Those who want to keep circulating have not yet decided on their final destination, and therefore have needs situated between those of the above two groups, something that should also be taken into account in the creation of housing security policies.

\section{The role of the state in providing housing security to migrants: some further conceptual and policy considerations}

As we have mentioned earlier, so far rural-urban migration has been understood mostly as a oneway flow where migrants leave their rural places of origin and settle in their destination cities. In accordance with such a conceptual framework, much of the discussion about social protection for China's migrants has been based on the analytical framework of urban integration and exclusion, focusing on the role of the hukou system in hindering the integration of migrants into destination cities (e.g. Solinger 1999; Zheng and Huang Li 2007). The analysis of migrants' housing issues is no exception. In fact, a similar concept of 'housing exclusion' has been introduced in the discussion on migrants' housing issues (Zhao 2008), suggesting that unreasonable policies and institutional arrangements are the determining factor in migrants' disadvantaged housing situation (e.g. Shen and Huang 2003), and that the best solution to this issue would be to include them in the existing urban housing security system, so that their housing rights can be secured (e.g. Zhang and Wang 2007).

However, recent studies suggest that while institutional arrangements and relevant policies are an important factor in this situation, they are not the only, or even the main one (Lin and Zhu 2008; Mark, Li and Peng 2008). In fact, one of the important conclusions from this study is that not all, and in many cases only a small proportion, of migrants want to settle down in the cities. Therefore, integration into the urban housing security system is not necessarily in their best interests. Thus, the inclusive approach of extending the existing urban housing security system to migrants as mentioned earlier, which is consistent with the analytical framework of 'housing exclusion', can only benefit the small proportion who have the intention and capacity to settle down in their destination cities. For those who intend to return to their hometowns in the future, and those who will remain in circulation for a prolonged period, new approaches are needed to suit their multi-local nature, and to ensure that their 'floating needs' for housing provision and housing security can be better met.

Such new approaches not only require differentiation among migrants and between migrants and local urban residents, but also raise an important issue: the need to establish a corresponding institutional basis for such diversity, with the state playing a bigger and coordinating role. This necessity arises from the following facts. First, as we have discussed above, so far, the state has played a minor role in the provision of housing security to migrants, and migrant employers are required to take the main responsibility. However, there are limits on what migrant employers, especially small enterprises, can do. In fact, our interviews with some employers suggest that the maximum cost that a small business can bear for an employee is only 
40 yuan/month, which could only produce a very limited improvement in migrant housing conditions (in-depth interview, record of the authors No. 4, May 2009). If substantive and significant improvement in migrants' housing situation is to be achieved, the state must gradually play a greater role and eventually take the main responsibility. Second, currently, the limited roles of the state in providing housing security to migrants are mostly borne by local governments of migrant destination cities, into which migrants are supposed to be integrated. However, migrants' multi-local nature suggests that they often have more than one destination city, in addition to their places of origin. In fact, migrants need to be integrated not only into a city, but rather into the whole society, and therefore an institutional arrangement at a level

\section{Notes}

* The corresponding author.

1 The calculation of the housing facility index is based on the method used in $\mathrm{Wu}$ (2002). It is equal to $\sum \mathrm{Xi} / 8$, where the values of $\mathrm{Xi}$ are defined as the following, respectively:

\section{References}

Chan, K.W. and Zhang L. (1999) 'The Hukou System and Rural-urban Migration in China: Processes and Changes', The China Quarterly 160: 818-55

Du, J. (2008) Shishi 'Lingzujin' Zhufang, Fujian Litui Nongmingong Juzheyouqiwu [Implementation of the 'Zero-rent' Housing: Fujian Vigorously Promotes Housing Security for Rural-urban Migrant Workers], www.66163.com/house/ newsinfo.php?id $=688 \&$ lanmu $=$ snxw (accessed 10 September 2008)

Jiang, Y.F.; Luo, J.J. and Wang, L. (2008) Guangdong Guiding Youxiu Nongmingong ke Jincheng Luohu, ke Xiang Lianzufang Zhengce [Regulations of Guangdong Province on Helping Excellent Rural-urban Migrant Workers to Settle Down in the Cities and Enjoy Low-rent Housing], http://news.163.com/08/0530/02/4D5KS6SS00 01124J.html (accessed 8 July 2008)

Liang, Q. (2005) Jianshebu Jiang Nongmingong Zhufangwenti Lieru Jinnian Gongzuo Zhongdian [Ministry of Construction Listed the Housing Issue of Rural-urban Migrant Workers as a Key of this Year's Work], http://house.focus.cn/newshtml/ 87762.html (accessed 10 July 2008)

Liang, Z. (2001) 'The Age of Migration in China', Population and Development Review 27: 499-524 higher than municipal governments is required to serve the coordinating role for providing housing security to migrants. Such an institutional arrangement should also be able to facilitate raising and providing funds for migrants' housing security; in fact, a cross-provincial or even national housing security fund could be established for such a purpose. At the same time, a clear legal and institutional framework defining migrants' housing rights and the obligations of governments at various levels for providing housing security to migrants should be developed at the national level, so that these provisions will not be dependent on the political will and financial capacity of destination cities. Only in this way can migrants' 'floating' housing needs be met by 'portable' housing security policies.

(Electricity/gas $0=$ no, $1=$ yes); (Tap water $0=$ no, $1=$ yes $) ;($ Kitchen $0=$ no, $1=$ shared, $2=$ private $) ;($ Lavatory $0=$ no, $1=$ shared, $2=$ private $) ;($ bathroom $0=$ no, $1=$ shared, $2=$ private $)$.

Lin, L.Y. and Zhu, Y. (2008) 'Living Status of the Floating Population and its Determinants in China: A Case Study of Fujian Province' [in Chinese], Renkou Yanjiu [Population Research] 32.3: 48-56

Mark, D.D.; Li, B.Q. and Peng, H.M. (2008) 'Household Strategies and Migrant Housing Quality in Tianjin', in I. Nielsen and R. Smyth (eds), Migration and Social Protection in China, Singapore: World Scientific Publishing

Ministry of Construction, Ministry of Finance and People's Bank of China (2005) Guanyu Zhufanggongijing Guanli Ruogan Wenti Zhidao Yijian [Guiding Opinions of Ministry of Construction, Ministry of Finance and People's Bank of China on the Issues Concerning the Public Reserve Fund Management], www.51labour.com/ lawcenter/lawshow-39434.html (accessed 20 July 2008)

Ministry of Construction, National Development and Reform Commission, Ministry of Finance, Ministry of Labour and Social Security and Ministry of Land and Resources (2007) Guanyu Gaishan Nongmingong Juzhu Tiaojian de Zhidao Yijian [Guiding Opinions on Improving Rural-urban Migrant Workers' Housing Conditions], www.51labour.com/lawcenter/lawshow75019.html (accessed 20 July 2008) 
Shen, J.F. and Huang, Y.F. (2003) 'The Working and Living Space of the Floating Population in China', Asia Panic Viewpoint 44.1: 51-62

Solinger, D.J. (1999) Contesting Citizenship in Urban China: Peasant Migrants, the State, and the Logic of the Market, Berkeley: University of California Press

The State Council (2006) Guanyu Jiejue Nongmingongwenti de Ruogan Yijian [A Few Opinions on Resolving the Issues of Rural-urban Migrant Workers], www.51labour.com/lawcenter/ lawshow-44300.html (accessed 20 July 2008)

Wu, W.P. (2002) 'Migrant Housing in Urban China: Choices and Constraints', Urban Affairs Review, September: 90-119

Zhang, G.S. and Wang, Z. (2007) 'A Comparative Study of Urban Housing Policy for Migrant Workers: Based on International Experience' [in Chinese], Zhongguo Ruankexue [China Soft Science] 12: 39-47

Zhao, Y.Q. (2008) 'Residency and Citizenship Treatment: The Fourth Group in Urban Redeveloping' [in Chinese], Shehuixue Yanjiu [Sociological Research] 2: 118-32

Zheng, G.C and Huang Li, R.L. (2007) Zhongguo Nongmingong Wenti yu Shehuibaohu [Rural-urban
Migrant Workers in China: Issues and Social Protection], Beijing: People's Press

Zhu, Y. (2007) 'China's Floating Population and their Settlement Intention in the Cities: Beyond the Hukou Reform', Habitat International 31.1: 65-76

Zhu, Y. (2003) 'The Floating Population's Household Strategy and the Migration's Role in China's Regional Development and Integration', International Journal of Population Geography 9.6: 485-502

Zhu, Y. and Chen, W.Z. (2010) 'The Settlement Intention of China's Floating Population in the Cities: Recent Changes and Multi-faceted Individual-level Determinants', Population, Space and Place 16.4: 253-67

Zhu, L. and Zhu, K.J. (2007) 'The Floating Population's Housing Conditions and the Relevant Social Policies', in X.M. Zhang (ed.), Hexieshehui Shiyexia de Jiangsu Renkou yu Fazhan [Population and Development in Jiangsu Province: Under a Harmonious Society], Nanjing: Nanjing University Press 